\title{
Ensaio sobre a dignidade humana enquanto essência da humanidade $^{1}$
}

\section{Essay on human dignity as the essence of humanity}

DOI: 10.54018/sssrv1n1-003

Recebimento dos originais: 06/01/2020

Aceitação para publicação: 31/01/2020

\section{Flávio Marcelo Rodrigues Bruno}

Pós-Doutor em Direito (Universitá degli Studi di Messina-ITA). Doutor em Direito (PPGD/UERJ-RJ). Mestre em Direito (PPGD/Puc-PR). Mestre em Economia (PPGE/Unisinos-RS). Especialização em Direito e Economia (PPGDPPGE/UFRGS). Líder do Grupo de Pesquisa "Direitos Fundamentais, Socioambientalismo e a Ordem Jurídica Internacional". Professor do Curso de Graduação em Direito e Pesquisador Credenciado ao Programa de PósGraduação em Ciências Humanas e Sociais - PPGCS, da Universidade Federal do Oeste da Bahia -UFOB.

\begin{abstract}
Sumário: Introdução. 1ำ ATO: direitos humanos e dignidade da pessoa humana enquanto valor e princípio fundamental. $2^{\circ}$ ATO: a dignidade da pessoa humana na ordem constitucional. 3ำ ATO: dignidade humana e a interpretação judicial dos direitos humanos. Considerações Finais. Referências.
\end{abstract}

\section{RESUMO}

Este trabalho constitui um ensaio temático que resta dividido em três atos, no primeiro são abordados os direitos humanos e a dignidade da pessoa humana enquanto valor e princípio fundamental; no segundo a dignidade da pessoa humana na ordem constitucional e no terceiro e último, a dignidade humana e a interpretação judicial dos direitos humanos. Tendo como objetivo nuclear, possibilitar uma visão reflexiva sobre a dignidade da pessoa humana. Como pano de fundo deste trabalho, real motivação do estado da arte e das indagações suscitadas ao logo do texto, está a instigação de reflexões, através de uma análise filosófico-histórica mais aprofundada do conceito de dignidade da pessoa humana enquanto essência da humanidade. Razão pela qual, este trabalho visa contribuir com a construção do conhecimento em relação à dignidade da pessoa humana.

Palavras-chave: Direito Constitucional; Direitos Fundamentais, Dignidade Humana.

\section{ABSTRACT}

This paper is a thematic essay divided into three acts. The first one deals with human rights and the dignity of the human person as a fundamental value and

\footnotetext{
1 Versão ampliada da originalmente publicada na coletânea, "Princípios de Direito Público: ênfase em Direito Financeiro e Tributário"- organizada por Marcus Abraham e Vítor Pimentel Pereira, lançada pela Editora Fórum, em Belo Horizonte, 2018.
} 
principle; the second one with human dignity in the constitutional order; and the third and last one with human dignity and the judicial interpretation of human rights. The nuclear objective is to enable a reflective view on the dignity of the human person. The background of this work, the real motivation of the state of the art and the questions raised throughout the text, is the instigation of reflection, through a deeper philosophical-historical analysis of the concept of dignity of the human person as the essence of humanity. For this reason, this paper aims to contribute to the construction of knowledge regarding the dignity of the human person.

Keywords: Constitutional Law; Fundamental Rights, Human Dignity.

\section{INTRODUÇÃO}

A dignidade da pessoa humana ocupa especial lugar na teoria do pensamento jurídico e nas principais reflexões acadêmicas e intelectuais contemporâneas. Não há uma única concepção sobre o conceito de dignidade, tampouco, limites à construção do conhecimento sobre o tema. Os direitos humanos seriam os atributos reconhecidos, em documentos internacionais, ao ser humano como tal, independentemente do direito constitucional do Estado, aspirando assim à validade universal, para todos os povos e tempos e ostentando inequívoco caráter supranacional, enquanto os direitos fundamentais são aqueles reconhecidos e positivados pelo direito constitucional de um determinado Estado. ${ }^{2}$

Num momento de pós-Segunda Guerra Mundial, fora renovada a concepção de direitos humanos no plano internacional, elevando os direitos fundamentais da pessoa a partir de movimentos que universlizaram a valorização humana. Nesse contexto, os direitos humanos expressam a mais evidente preocupção ao afirmar a centralidade da dignidade humana perante outros valores acolhidos pelo direito no decorrer da história. O período posterior à guerra significou a vontade de reconstrução e validação de direitos e valores negligenciados durante o período de guerra. Reiterando pelo mundo o a importância de se proteger a dignidade humana.

Um princípio é por definição, um mandamento nuclear de um sistema, real alicerce de disposições fundamentais, um verdadeiro núcleo do próprio ordenamento jurídico. A dignidade da pessoa humana concebe a valorização da pessoa humana como sendo razão fundamental para a estruturação de

2 SARLET, Ingo Wolfgang. A Eficácia dos Direitos Fundamentais. Porto Alegre. Livraria do advogado. Editora Ltda, 2005, p.35. 
organização do Estado e para o Direito. ${ }^{3}$

O presente estudo, não se permite esgotar a temática, tampouco tem qualquer pretensão nesse sentido. Desta forma, este trabalho constitui um ensaio temático que resta dividido em três atos, no primeiro são abordados os direitos humanos e a dignidade da pessoa humana enquanto valor e princípio fundamental; no segundo a dignidade da pessoa humana na ordem constitucional e no terceiro e último, a dignidade humana e a interpretação judicial dos direitos humanos. Tendo como objetivo nuclear, possibilitar uma visão reflexiva sobre a dignidade da pessoa humana, fruto de leituras, apontamentos, debates e pesquisas realizadas no âmbito acadêmico.

\section{1ํ ATO: DIREITOS HUMANOS E DIGNIDADE DA PESSOA HUMANA ENQUANTO VALOR E PRINCÍPIO FUNDAMENTAL.}

Os direitos humanos seriam os atributos reconhecidos, em documentos internacionais, ao ser humano como tal, independentemente do direito constitucional do Estado, aspirando assim à validade universal, para todos os povos e tempos e ostentando inequívoco caráter supranacional, enquanto os direitos fundamentais são aqueles reconhecidos e positivados pelo direito constitucional de um determinado Estado. ${ }^{4}$

Num momento de pós-Segunda Guerra Mundial, fora renovada a concepção de direitos humanos no plano internacional, elevando os direitos fundamentais da pessoa a partir de movimentos que universlizaram a valorização humana. Nesse contexto, os direitos humanos expressam a mais evidente preocupção ao afirmar a centralidade da dignidade humana perante outros valores acolhidos pelo direito no decorrer da história. O período posterior à guerra significou a vontade de reconstrução e validação de direitos e valores negligenciados durante o período de guerra. Reiterando pelo mundo o a importância de se proteger a dignidade humana.

Um princípio é por definição, um mandamento nuclear de um sistema, real alicerce de disposições fundamentais, um verdadeiro núcleo do próprio

\footnotetext{
${ }^{3}$ GUERRA, Sidney; EMERIQUE, Lilian Márcia Balmant. O princípio da dignidade da pessoa humana e o mínimo existencial. Revista da Faculdade de Direito de Campos, Ano VII, № 9 Dezembro de 2006.

${ }^{4}$ SARLET, Ingo Wolfgang. A Eficácia dos Direitos Fundamentais. Porto Alegre. Livraria do advogado. Editora Ltda, 2005, p.35.
} 
ordenamento jurídico. A dignidade da pessoa humana concebe a valorização da pessoa humana como sendo razão fundamental para a estruturação de organização do Estado e para o Direito. ${ }^{5}$

O princípio da diginidade humana transcende os limites do positivismo, um dos mais fundamentais princípios constitucionais, o seu respeito obriga irrestrita e incontornavelmente o Estado a considerar tudo que contrarie os valores da dignidade, como juridicamente nulo ${ }^{6}$. Tido por Barcellos ${ }^{7}$ como um axioma da civilização ocidental, "talvez a única ideologia remanescente". É a partir desta concepção, que assevera Sarmento ${ }^{8}$, que o Estado tem não apenas um dever de se abster de práticas contrárias à dignidade humana, como também deve promover esta dignidade através de condutas ativas que garantam o mínimo existencial para cada ser humano em seu território.

É imposto ao Estado respeitar, proteger e promover condições que viabilizem a vida com dignidade, mas não apenas isso, Sarlet $^{9}$ ampliou essa vinculação, no sentido de que também na ordem comunitária, todas as entidades privadas e os particulares encontram-se diretamente vinculados pelo princípio da dignidade da pessoa humana, especialmente importante em tempos de globalização econômica. No mesmo sentido, Rocha ${ }^{10}$ afirma que a dignidade humana consubstancia um verdadeiro "superprincípio constitucional", uma norma matriz do constitucionalismo contemporâneo. Descreve da mesma forma, Silva ${ }^{11}$ no sentido de que a dignidade da pessoa humana seria um valor supremo da democracia.

A dignidade da pessoa humana resulta do fato de que, racionalmente, somente a pessoa vive em condições de autonomia, ou seja, é como ser capaz

\footnotetext{
${ }^{5}$ GUERRA, Sidney; EMERIQUE, Lilian Márcia Balmant. O princípio da dignidade da pessoa humana e o mínimo existencial. Revista da Faculdade de Direito de Campos, Ano VII, № 9 Dezembro de 2006.

6 PIOVESAN, Flávia; VIEIRA, Renato Stanziola. A força normativa dos princípios constitucionais fundamentais: a dignidade da pessoa humana. In: PIOVESAN, Flávia. Temas de direitos humanos. 3. ed. São Paulo: Saraiva, 2009.

${ }^{7}$ BARCELLOS, Ana Paula de. A eficácia jurídica dos princípios constitucionais: o princípio da dignidade da pessoa humana. Rio de Janeiro: Renovar, 2002. p.103-104.

8 SARMENTO, Daniel. A ponderação de interesses na Constituição. Rio de Janeiro: Lúmen Juris, 2000.

9 SARLET, Ingo. Dignidade da Pessoa Humana e Direitos Fundamentais na Constituição Federal de 1988. 4⿳亠丷厂 ed. Livraria do Advogado: Porto Alegre, 2006. p. 109-140.

${ }_{10}$ ROCHA, Cármen Lúcia Antunes. O princípio da dignidade da pessoa humana e a exclusão social, texto mimeografado, em palestra proferida na XVII Conferência Nacional da Ordem dos Advogados do Brasil, Rio de Janeiro, 29-8-1999. p.8-9.

11 SILVA, José Afonso da. Poder constituinte e poder popular. São Paulo: Malheiros, 2000.
} 
de guiar-se pelas leis que autodetermina. Razão pela qual, afirma Comparato ${ }^{12}$, que "todo o homem tem dignidade e não um preço, como as coisas".

Ao abordar a dignidade como limite e tarefa do Estado, da comunidade e dos particulares, o Sarlet ${ }^{13}$ esclarece que não pode o individuo abrir mão de sua dignidade em nenhuma hipótese. E que, em proteção a dignidade humana, cabem inclusive decisões que reconhecem limitações à liberdade individual, especialmente no campo da autonomia privada e liberdade contratual, inclusive no sentido de uma proteção da pessoa contra si mesma.

Sobre a proteção pela dignidade e o problema dos limites da dignidade é necessário se determinar que esta a se referir sobre a função da dignidade como limitadora das restrições dos direitos fundamentais. Afirmando que só se poderá falar em proteção dos direitos fundamentais por meio da dignidade da pessoa. ${ }^{14}$ Cumpre o princípio da dignidade da pessoa humana uma dupla função: serve como importante elemento de proteção dos direitos contra medidas restritivas e abusos de direitos; ao passo que também serve como uma justificativa para a imposição de restrições a direitos fundamentais, acabando por atuar como elemento limitador destes direitos fundamentais. ${ }^{15}$

$\mathrm{Na}$ abordagem da discussão em torno do caráter absoluto da dignidade e da possibilidade de sua eventual relativização, o autor então aborda as possibilidades de impor limites à própria dignidade humana. Ao buscar efetivar a dignidade de uma pessoa não se estaria limitando a dignidade de outra? É a principal indagação. E em se partindo do ponto de vista que a dignidade, sendo inerente à essência do ser humano, se constitui em bem jurídico absoluto, inalienável, irrenunciável e intangível parece não perceber qualquer possibilidade de relativização. Mas em análise social de convívio em grupo, ao proteger a dignidade de uma pessoa, limita-se a de outra igualmente digna. ${ }^{16}$

12 COMPARATO, Fábio Konder. A afirmação histórica dos direitos humanos. São Paulo: Saraiva, 1999. p.20.

13 SARLET, Ingo. Dignidade da Pessoa Humana e Direitos Fundamentais na Constituição Federal de 1988. 4 ${ }^{\mathrm{a}}$ ed. Livraria do Advogado: Porto Alegre, 2006. p. 115

${ }^{14}$ SARLET, Ingo. Dignidade da Pessoa Humana e Direitos Fundamentais na Constituição Federal de 1988. 4⿳亠丷厂 ed. Livraria do Advogado: Porto Alegre, 2006. p. 120.

15 SARLET, Ingo. Dignidade da Pessoa Humana e Direitos Fundamentais na Constituição

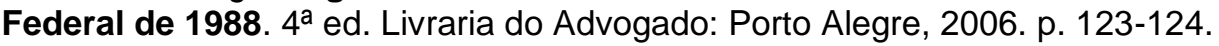

16 SARLET, Ingo. Dignidade da Pessoa Humana e Direitos Fundamentais na Constituição Federal de 1988. $4^{\mathrm{a}}$ ed. Livraria do Advogado: Porto Alegre, 2006. p. 125. 
Sarlet ${ }^{17}$ é feliz ao afirmar que na atualidade não há como negar que a dignidade da pessoa humana é desconsiderada, desrespeitada, violada e desprotegida, seja pelo incremento da violência contra a pessoa, seja pela carência social, econômica e cultural, um falta de compromisso com as condições mínimas de existência para uma vida com dignidade e humanidade.

$\mathrm{Na}$ concepção de Sousa Santos ${ }^{18}$ os direitos humanos constituem-se de uma hegemonia frágil, mesmo com o tema sendo amplamente debatido nos discursos acadêmicos do direito, da política, e da cultura.

a hegemonia dos direitos humanos como linguagem de dignidade humana é hoje incontestável. No entanto, esta hegemonia convive com uma realidade perturbadora. A grande maioria da população mundial não é sujeito de direitos humanos, é objeto de discursos de direitos humanos ${ }^{19}$

Nesse sentido, há de se referir à visão de $A$ exy ${ }^{20}$, de que até mesmo o princípio da dignidade da pessoa humana acaba por sujeitar-se, em sendo contraposto à igual dignidade de terceiros, a uma necessária relativização. Proteger de modo absoluto a dignidade de todas as pessoas na forma da igualdade apenas será possível enquanto se estiver falando na dignidade como a capacidade ou potencialidade para a autoderminação, muito embora, no plano das relações interpessoais concretas, não há como evitar a necessidade de se estabelecer limites ao livre desenvolvimento da personalidade, razão pela qual alguns tribunais encontram possibilidade de sujeitar a dignidade humana às restrições. ${ }^{21}$

Na seara da discussão é necessário se advertir que nem a maioria da doutrina e da jurisprudência considera as restrições à dignidade uma própria violação da dignidade, e que nenhum interesse comunitário poderá justificar ofensa à dignidade individual, esta considerada como valor absoluto e

\footnotetext{
17 SARLET, Ingo. Dignidade da Pessoa Humana e Direitos Fundamentais na Constituição Federal de 1988. $4^{\mathrm{a}}$ ed. Livraria do Advogado: Porto Alegre, 2006. p. 126.

18 SANTOS, Boaventura de Sousa. Se Deus fosse um ativista de direitos humanos. Cortez Editora, 2013.

19 SANTOS, Boaventura de Sousa. Se Deus fosse um ativista de direitos humanos. Cortez Editora, 2013. p.15.

${ }^{20}$ ALEXY, Robert. Teoria dos direitos fundamentais. Tradução Virgílio Afonso da silva. São Paulo: Malheiros, 2008.

${ }^{21}$ SARLET, Ingo. Dignidade da Pessoa Humana e Direitos Fundamentais na Constituição Federal de 1988. $4^{\mathrm{a}}$ ed. Livraria do Advogado: Porto Alegre, 2006. p. 132-133.
} 
insubstituível de cada ser humano. ${ }^{22}$

Em se admitindo certo grau de relativização da dignidade da pessoa humana, se assumirá que a própria dignidade da pessoa humana como norma jurídica fundamental é possuidora de um núcleo essencial e, portanto, intangível. Nesta linha de raciocínio, somente na hipótese de uma desconsideração inequívoca de seu valor intrínseco como ser humano, em sua condição de sujeito, restaria configurada uma efetiva violação da dignidade humana. Não sendo isso, seriam todas as consideradas violação ou restrições à dignidade, eventuais ofensas a outros direitos fundamentais.

$\mathrm{Na}$ visão de Sarlet $^{23}$, a dignidade da pessoa humana na condição de princípio tolera certo grau de relativização, respeitado, todavia, sempre também o núcleo essencial em dignidade, este sim dotado do atributo da intangibilidade. Essa visão se fortalece na ideia de que é vedada qualquer conduta de coisificação e instrumentalização do ser humano - que é fim, e não meio. É plausível tolerar alguma relativização, com a necessidade de respeitar, proteger e promover a igual dignidade de todas as pessoas, não olvidando que, antes de ser norma jurídica, a dignidade é uma qualidade intrínseca do ser humano - o que o torna titular de pretensão de respeito e proteção.

Visualizando uma dupla dimensão negativa e positiva da dignidade da pessoa humana. E desta forma, se na sua condição de direito de defesa não se deverá jamais aceitar uma violação da dignidade - de seus elementos nucleares - mesmo que em função de outra dignidade; por sua vez, pelo prisma positivo, verifica-se que não há como deixar de admitir a existência de uma larga margem de liberdade por parte dos órgãos estatais para além de respeitar, proteger a dignidade de todas as pessoas, bem como de promover a efetiva condição de vida digna para todos. O que a depender das circunstancias concretas deixará margens para uma inevitável relatividade da dignidade, ao menos em sua condição jurídico-normativa.

Em Kant ${ }^{24}$ os seres que não são dotados de razão e que dependem da

22 SARLET, Ingo. Dignidade da Pessoa Humana e Direitos Fundamentais na Constituição Federal de 1988. $4^{\mathrm{a}}$ ed. Livraria do Advogado: Porto Alegre, 2006. p. 134.

23 SARLET, Ingo. Dignidade da Pessoa Humana e Direitos Fundamentais na Constituição Federal de 1988. $4^{\mathrm{a}}$ ed. Livraria do Advogado: Porto Alegre, 2006. p. 137-138.

${ }^{24}$ KANT, Immanuel. Fundamentação da Metafísica dos Costumes. São Paulo: Martin Claret, 2008. p.69 
natureza para existir, são coisas que representam valor relativo, visto serem de meio e não de fim. Não se assume isso com pessoas humanas que possuem um valor em si mesmo. Assim, o respeito à dignidade do homem está diretamente relacionado com a noção de humanidade, e como afirma o referido autor: "se deve agir de tal maneira que uses a humanidade, tanto na tua pessoa como na de outra qualquer, sempre e simultaneamente como fim e nunca simplesmente como meio"

Este valor inerente à pessoa humana advém não só do simples fato de sua existência, mas também da possibilidade de gerir os atos de sua vida, situação que lhe confere dignidade. Neste sentir, a dignidade é um valor presente em todas as pessoas humanas e por isto pode-se afirmar que o tratamento igualitário do homem independente de suas características pessoais, mas sim de sua natureza racional que lhe dá capacidade de tomar as decisões relacionadas com a sua própria vida.

A concretização da dignidade como um valor inerente à pessoa humana se dá quando o legislador constituinte o reconhece como um princípio que ordenará todo o sistema jurídico nacional. Este reconhecimento pode ser expresso ou implícito no texto legal, o que importa é que as ações do Estado estejam voltadas para o respeito do homem como a figura central do ordenamento jurídico. $O$ princípio da dignidade da pessoa humana evoca a valorização do homem frente aos seus pares e o Estado, por este motivo inúmeros instrumentos internacionais trataram de reconhecê-lo internacionalmente, a fim de que os países seguissem a mesma orientação no plano interno ${ }^{25}$.

A dignidade de alguma forma situa-se em nível mais profundo na essência do homem, de modo que a liberdade lhe será subsumida. Essa constatação sobre a natureza última da "dignidade humana" escreve Edelman ${ }^{26}$, constituiu-se numa "descoberta maior" do que aquela dos próprios direitos humanos. Verifica-se então como a dignidade humana encontra-se referida à questão não do indivíduo,

25 O termo dignidade encontra-se em muitos textos internacionais: Declaração Universal dos Direitos do Homem, 1949, art. 22; Convenção relativa aos direitos da Criança, 1959, art. 39; Pacto Internacional relativo aos direitos civis e políticos, 1966, art. 10; Declaração Universal sobre o Genoma Humano e os Direitos Humanos, 1997, Parte A, art. 2. Mas não figura na declaração da independência dos Estados Unidos e nem na declaração revolucionária francesa de 1789 e, tampouco, nos textos posteriores, durante quase dois séculos. No entanto, esteve sempre presente como princípio, referência moral obrigatória quando, ainda no Século 19, a escravidão era combatida por ser um atentado contra a dignidade humana.

${ }^{26}$ EDELMAN, Bernard. La dignité de la personne humaine, un concept nouveau. In: PAIVA, M.-L.; REVETT, Thierry. (Dir), La dignité de la personne. Paris : Econômica, 1999. 
mas da humanidade. Preceitua Edelman, "se a liberdade é a essência dos direitos humanos, a dignidade é a essência da humanidade"

\section{2 ATO: A DIGNIDADE DA PESSOA HUMANA NA ORDEM}

\section{CONSTITUCIONAL.}

Há uma dificuldade objetiva de definições sobre a dignidade da pessoa humana. De forma muito breve, ao abordar a origem e evolução da dignidade da pessoa humana, o Barroso ${ }^{27}$ é objetivo, busca demonstrar os caminhos que levaram a temática a uma abstração de conceituação. A dignidade da pessoa humana, ao partir de uma origem religiosa, migrar para a filosofia, tornar-se objetivo político e, ao adentrar no mundo jurídico é que se torna objeto de debate significativo em razão de uma visão pós-positivista aliada a sua inclusão em documentos internacionais e cartas políticas democráticas.

É inegável que uma das linhas construtivas do conceito de dignidade da pessoa humana iniciou-se pela contribuição de valores religiosos. A fé monoteísta judaico-cristã muito contribuiu para a formação do conceito de dignidade da pessoa humana, como visto em Abraham e Pereira ${ }^{28}$, sendo a principal matriz do homem moderno ocidental ver a si mesmo e ao mundo a sua volta.

Mesmo considerando toda uma construção história anterior, a maioria da doutrina remete primeira referência direta a dignidade humana à Mirandola ${ }^{29}$, defendia o autor que o homem ocupa um lugar especial no cosmos, e consagra a autonomia da vontade, matriz do princípio da dignidade humana:

Não te fizemos celeste nem terreno, nem mortal, nem imortal, a fim de que tu, árbitro e soberano artífice de ti mesmo, te plasmasses e te informasses, na forma que tivesses seguramente escolhido. Poderás degenerar até aos seres que são as bestas, poderás regenerar-te até às realidades superiores que são divinas, por decisão do teu ânimo

27 BARROSO, Luís Roberto. A Dignidade da Pessoa Humana no Direito Constitucional Contemporâneo: Natureza Jurídica, Conteúdos Mínimos e Critérios de Aplicação. Versão provisória para debate público. Mimeografado, dezembro de 2010. p. 4.

${ }^{28}$ ABRAHAM, Marcus; PEREIRA, Vítor Pimentel. A influência da Torá nas Instituições Jurídicas Brasileiras. Revista do Instituto Histórico e Geográfico Brasileiro. Rio de Janeiro, a. 176. n. 466, pp. 11-270, jan./mar. 2015.

29 MIRANDOLA, Giovanni Pico Della. Discurso sobre a dignidade do homem. Tradução de Maria de Lurdes Sigardo Ganho. Lisboa: Edições 70, 1989. 
A definição mais aceita e trabalhada amplamente é a de Kant ${ }^{30}$, que sustenta que tudo o que não é passível de valor não estaria de acordo com a dignidade, assim, todo o ser racional não pode servir como meio à consecução de algum objetivo, posto ser dotado de dignidade. O conceito fundamental de dignidade presente na Fundamentação como valor "íntimo" e "incondicional" revela-se surpreendentemente similar à definição que lhe dá Tomás de Aquino como a bondade que uma coisa possui "por si mesma". ${ }^{31}$

Desta forma, é o princípio da dignidade da pessoa humana constituiu a fonte legitimadora de todos os outros direitos fundamentais. No entanto, Barroso ${ }^{32}$ situa o tema, enquanto valor consensual moral contemporâneo, numa "necessidade de se fixar o sentido e alcance da dignidade humana, como elemento argumentativo necessário à produção da solução justa". O que agrava as dificuldades de sua utilização enquanto instrumento relevante de interpretação jurídica.

A dignidade da pessoa humana é autopoiética ${ }^{33}$ e em constante processo de mutação ${ }^{34}$. Razão pela qual sofreu críticas em relação a sua utilização, dotada de aspectos culturais, históricos, políticos e ideológicos já fora tida como vazia, ambígua e inútil. Inclusive somada a valores socialistas em que sua incompatibilidade com o constitucionalismo fora suscitado. ${ }^{35}$

Ao abordar sobre a natureza jurídica da dignidade da pessoa humana Barroso ${ }^{36}$ reforça os argumentos construtivos do caminho traçado pela temática ao longo do tempo. Inicialmente com o valor axiológico relacionado ao conceito de dignidade da pessoa humana do ponto de vista filosófico - associado então a

\footnotetext{
${ }^{30}$ KANT, Immanuel. Fundamentação da Metafísica dos Costumes. São Paulo: Martin Claret, 2008.

${ }^{31}$ ROSEN, Michael. Dignidade: sua história e significado. Tradução de André de Godoy Vieira. São Leopoldo: Editora Unisinos, 2015.

32 BARROSO, Luís Roberto. A Dignidade da Pessoa Humana no Direito Constitucional Contemporâneo: Natureza Jurídica, Conteúdos Mínimos e Critérios de Aplicação. Versão provisória para debate público. Mimeografado, dezembro de 2010. p. 2.

${ }^{33} \mathrm{Na}$ visão sistêmica de Niklas Luhmann, Günther Teubner que veem em Maturana e Varela a autopoiésis do Direito.

${ }^{34}$ Como muitos dos valores democráticos contemporâneos - democracia, fraternidade, liberdade - em Chantal Mouffe.

35 BARROSO, Luís Roberto. A Dignidade da Pessoa Humana no Direito Constitucional Contemporâneo: Natureza Jurídica, Conteúdos Mínimos e Critérios de Aplicação. Versão provisória para debate público. Mimeografado, dezembro de 2010. p. 8.

36 BARROSO, Luís Roberto. A Dignidade da Pessoa Humana no Direito Constitucional Contemporâneo: Natureza Jurídica, Conteúdos Mínimos e Critérios de Aplicação. Versão provisória para debate público. Mimeografado, dezembro de 2010. p. 10.
} 
valores essenciais como justiça, segurança, bom e solidário. Na visão política é considerada um fundamento do Estado Democrático de Direito e integrante de documentos constitucionais e importantes tratados internacionais. Sem deixar de ser um valor fundamental a dignidade da pessoa humana é alçada a princípio jurídico. A interlocução entre moral e Direito é o fundamento do pós-positivismo e importante para a convicção sobre a dignidade da pessoa humana enquanto princípio jurídico de estatura constitucional - mandamento de otimização sujeito à ponderação e à proporcionalidade - sendo que "sua pretensão normativa pode ceder, conforme as circunstâncias, a elementos contrapostos"37.

Três colocações são muito relevantes sobre a temática, à primeira é em relação à dignidade da pessoa humana como conteúdo dos direitos materialmente fundamentais, não se confundindo com qualquer deles. Esclarecendo que a dignidade da pessoa humana é um parâmetro e ponderação para a concorrência entre direitos fundamentais. Em segundo a dignidade da pessoa humana enquanto valor ou princípio fundamental não tem caráter absoluto. E por fim, é aplicável tanto nas relações entre indivíduo e Estado como nas relações privadas $^{38}$.

Na construção de um conteúdo mínimo da ideia de dignidade humana, o autor aborda a influência do pensamento kantiano, considerando os conceitos de autonomia - vontade livre, capacidade de se autodeterminar em conformidade com as leis; e de dignidade - aquilo acima de qualquer valoração equivalente como é o caso da pessoa humana.

Como consectário desse raciocínio, é possível formular uma outra enunciação do imperativo categórico: toda pessoa, todo ser racional existe como um fim em si mesmo, e não como meio para o uso arbitrário pela vontade alheia [...] Este princípio do indivíduo como fim em si mesmo !é a condição suprema que limita a liberdade das ações de cada homem! ${ }^{39}$ Na formulação mais analítica do autor: "Os seres cuja existência depende, não em verdade da nossa vontade, mas da natureza, têm, contudo, se são seres

37 BARROSO, Luís Roberto. A Dignidade da Pessoa Humana no Direito Constitucional Contemporâneo: Natureza Jurídica, Conteúdos Mínimos e Critérios de Aplicação. Versão provisória para debate público. Mimeografado, dezembro de 2010. p. 11.

38 BARROSO, Luís Roberto. A Dignidade da Pessoa Humana no Direito Constitucional Contemporâneo: Natureza Jurídica, Conteúdos Mínimos e Critérios de Aplicação. Versão provisória para debate público. Mimeografado, dezembro de 2010. p. 14-15.

39 BARROSO, Luís Roberto. A Dignidade da Pessoa Humana no Direito Constitucional Contemporâneo: Natureza Jurídica, Conteúdos Mínimos e Critérios de Aplicação. Versão provisória para debate público. Mimeografado, dezembro de 2010. p. 17-18. 
irracionais, apenas um valor relativo como meios e por isso se chamam coisas, ao passo que os seres racionais se chamam pessoas, porque a sua natureza os distingue já como fins em si mesmos, quer dizer como algo que não pode ser empregado como simples meio e que, por conseguinte, limita nessa medida todo o arbítrio" 40

Desta forma, a conduta ética consiste em agir inspirado por uma máxima que possa ser convertida em lei universal; todo homem é um fim em si mesmo, não devendo ser funcionalizado a projetos alheios; as pessoas humanas não têm preço nem podem ser substituídas, possuindo um valor absoluto, ao qual se dá o nome de dignidade ${ }^{41}$.

Ao refletir sobre o conceito para a dignidade humana, o Barroso ${ }^{42}$. afirma que se deve pensar em um conceito aberto em que vigora a plasticidade e a universalidade. Não sendo possível limitá-la a uma definição estritamente jurídica, já que permeia uma ampla diversidade de temáticas sociais. Atenta para que a dignidade humana seja atribuída de laicidade, neutralidade política, seus conteúdos sejam universalizáveis, multiculturais. Evocando uma tentativa civilizatória que determina fraternidade, consciência, tolerância, paciência e perseverança. Essa forma conceitual da dignidade humana é refletida em inúmeros documentos internacionais que vão da Declaração Universal dos Direitos Humanos até documentos dos regionalismos integracionais.

Ao buscar atribuir um sentido mínimo a dignidade da pessoa humana Barroso ${ }^{43}$ aponta três conteúdos essências da dignidade: o valor intrínseco, a autonomia e o valor social da pessoa humana. O valor intrínseco é abordado em dois planos, o filosófico no sentido de que a dignidade é um comum e inerente a todos os seres humanos - sendo o homem um fim em si mesmo, o Estado existe para o indivíduo e independe de qualquer razão. No plano jurídico se impõe a inviolabilidade da dignidade - e cita o direito à vida; o direito à igualdade; o direito

40 KANT, Immanuel. Immanuel Kant, Fundamentação da metafísica dos costumes, 2004, p. 71 e 68.

41 BARROSO, Luís Roberto. A Dignidade da Pessoa Humana no Direito Constitucional Contemporâneo: Natureza Jurídica, Conteúdos Mínimos e Critérios de Aplicação. Versão provisória para debate público. Mimeografado, dezembro de 2010. p. 18.

42 BARROSO, Luís Roberto. A Dignidade da Pessoa Humana no Direito Constitucional Contemporâneo: Natureza Jurídica, Conteúdos Mínimos e Critérios de Aplicação. Versão provisória para debate público. Mimeografado, dezembro de 2010. p. 19-20.

43 BARROSO, Luís Roberto. A Dignidade da Pessoa Humana no Direito Constitucional Contemporâneo: Natureza Jurídica, Conteúdos Mínimos e Critérios de Aplicação. Versão provisória para debate público. Mimeografado, dezembro de 2010. p. 22-23. 
à integridade física e o direito à integridade moral ou psíquica.

A autonomia relacionada ao elemento ético da dignidade, ligado à razão e ao exercício da vontade na conformidade de determinadas condutas. Nesse sentido, envolve a autodeterminação para mínimas condições de exercício de direitos pessoais o que inclui a ausência de privações essenciais. Em sua dimensão jurídica, a autonomia é exercida no plano privado - citando a liberdade, a igualdade; e também no plano público - citando os direitos políticos ${ }^{44}$.

É importante se fazer uma referencia ao direito ao mínimo existencial "direitos fundamentais a condições de vida" na medida em que necessários ao desfrute, em igualdade de chances, dos demais direitos fundamentais ${ }^{45}$. $O$ Barroso ${ }^{46}$, reitera que "o mínimo existencial constitui o núcleo essencial dos direitos fundamentais em geral e seu conteúdo corresponde às pré-condições para o exercício dos direitos individuais e políticos, da autonomia privada e pública", e nesse sentido, evoca os direitos à educação, à saúde, a assistência, ao acesso à justiça.

É importante destacar também que segundo o McCrudden 47 ., uma teoria sobre os direitos humanos, para ser bem-sucedida, deveria cumprir sete pontos, nos seguintes termos:

"It would need, probably, to be one (i) that gives a coherence to the concept of human rights so that the whole is greater than simply the sum of its parts, and not just a ragbag

${ }^{4}$ BARROSO, Luís Roberto. A Dignidade da Pessoa Humana no Direito Constitucional Contemporâneo: Natureza Jurídica, Conteúdos Mínimos e Critérios de Aplicação. Versão provisória para debate público. Mimeografado, dezembro de 2010. p. 24.

45 HABERMAS, Jürgen. Direito e democracia: entre facticidade e validade, 1997, v. 1, p. 160.

46 BARROSO, Luís Roberto. A Dignidade da Pessoa Humana no Direito Constitucional Contemporâneo: Natureza Jurídica, Conteúdos Mínimos e Critérios de Aplicação. Versão provisória para debate público. Mimeografado, dezembro de 2010. p. 25-26.

${ }^{47}$ Tradução livre: "Ela deveria, provavelmente, ser de tal modo (i) que dê coerência ao conceito de direitos humanos, de forma que o todo seja maior que a simples soma das suas partes, e não apenas uma coleção de direitos separados e desconexos; (ii) que não seja enraizada em nenhuma região particular do globo e apele para além das culturas, sem deixar de ser sensível às diferenças, (iii) que coloque a importância na pessoa, e não nos atributos de qualquer pessoa em particular, mas que também situe o indivíduo dentro de uma dimensão social; (iv) que não seja dependente dos direitos humanos originários apenas do exercício da autoridade estatal (o que não é menos importante, porque o que o Estado dá, ele também pode tirar); (v) que não seja ideológico (no sentido de que transcenda qualquer conflito particular, como entre o capitalismo e o comunismo); (vi) que seja humanista (no sentido que não está baseada em quaisquer princípios ou crenças religiosas em particular, mas, apesar disso, mantém-se consistente com eles); (vii) que é, ao mesmo tempo, atemporal, no sentido de que incorpora valores básicos que não estão sujeitos a mudanças, e adaptável a mudar de ideias sobre o que envolve o ser humano". McCRUDDEN, Cristopher. Human dignity and judicial interpretation of human rights. The European Journal of International Law 19:655, 2008. p. 677. 
collection of separate unconnected rights, (ii) that is not rooted in any particular region of the globe and appeals across cultures, but is sensitive to difference, (iii) that places importance on the person rather than the attributes of any particular person, but that also places the individual within a social dimension, (iv) that is not dependent on human rights originating only from the exercise of state authority (not least because what the state gives the state can also take away), (v) that is non-ideological (in the sense that it transcends any particular conflicts, such as between capitalism and communism), (vi) that is humanistic (in the sense that it was not based on any particular set of religious principles or beliefs but is nevertheless consistent with them), and (vii) that is both timeless, in the sense that it embodies basic values that are not subject to change, and adaptable to changing ideas of what being human involves"

O valor social da pessoa humana é relacionado à dignidade como valor comunitário - elemento social que tem o indivíduo que vive em sociedade. Assim, a dignidade é o molde de uma vida coletiva pautada em prol de uma vida boa. $\mathrm{E}$ nesse sentido:

A dignidade como valor comunitário destina-se a promover objetivos diversos, dentre os quais se destacam: a) a proteção do próprio indivíduo contra atos autorreferentes; b) a proteção de direitos de terceiros; e c) a proteção de valores sociais, inclusive a solidariedade. É aqui que se situa a dimensão ecológica da dignidade, que tem sido objeto de crescente interesse, abrangendo diferentes aspectos da proteção ambiental e dos animais não humanos ${ }^{48}$

Trata-se de uma abordagem tocante à proteção do indivíduo em face de si mesmo, de suas próprias decisões e que é passível de uma imposição coercitiva de valores sociais, em nome de uma dimensão comunitária da dignidade, jamais uma providência banal, exigindo fundamentação racional consistente. Alertando que deve-se levar seriamente em conta: a) a existência ou não de um direito fundamental em questão; b) a existência de consenso social forte em relação ao tema; e c) a existência de risco efetivo para o direito de outras pessoas. A dignidade de um indivíduo jamais poderá ser suprimida, seja por ação própria ou de terceiros. Mas aspectos relevantes da dignidade poderão ser paralisados em

48 BARROSO, Luís Roberto. A Dignidade da Pessoa Humana no Direito Constitucional Contemporâneo: Natureza Jurídica, Conteúdos Mínimos e Critérios de Aplicação. Versão provisória para debate público. Mimeografado, dezembro de 2010. p. 28. 
determinadas situações ${ }^{49}$.

\section{3 ATO: DIGNIDADE HUMANA E A INTERPRETAÇÃO JUDICIAL DOS DIREITOS HUMANOS.}

A dignidade da pessoa humana desempenha papel central nos ordenamentos de países desenvolvidos e em desenvolvimento, e tem sido invocada com frequência cada vez maior por cortes constitucionais estrangeiras de todos os continentes e por tribunais internacionais. O estudo elaborado por McCrudden ${ }^{50}$ é singular, uma referência fundamental sobre o tema. Mas também um estudo de direito comparado, de história da instituição e da aplicação jurisprudencial da dignidade da pessoa humana.

Ao longo dos anos, muitas foram às definições dos pensadores. $\mathrm{Na}$ antiguidade clássica a dignidade era algo apreciado a partir da posição social que o indivíduo ocupava e o grau de reconhecimento que ele detinha na sociedade, de tal maneira era plenamente possível e plausível falar-se de pessoas com um grau maior ou menor de dignidade. Foi somente no final da segunda década do Século 20 que a dignidade humana passou a figurar em documentos jurídicos, a começar pelas Constituições do México (1917) e da Alemanha de Weimar $(1919)^{51}$.

É depreendida uma especial atenção ao tratamento da dignidade humana na Carta das Nações Unidas, na Declaração Universal dos Direitos Humanos e em inúmeros documentos de direito humanitário internacional, advindos de uma ordem internacional contemporânea. Que não é pretensão deste trabalho, mas que pode ser visitada em McCrudden ${ }^{52}$.

A demonstração da Dignidade da pessoa humana no Direito Comparado e no discurso transnacional esclarece a relevância do tema em tribunais de diversos países, e estabelece a dimensão transnacional da dignidade humana ${ }^{53}$. A

\footnotetext{
49 BARROSO, Luís Roberto. A Dignidade da Pessoa Humana no Direito Constitucional Contemporâneo: Natureza Jurídica, Conteúdos Mínimos e Critérios de Aplicação. Versão provisória para debate público. Mimeografado, dezembro de 2010. p. 30.

${ }^{50}$ MCCRUDDEN, Cristopher. Human dignity and judicial interpretation of human rights. The European Journal of International Law 19:655, 2008.

${ }^{51}$ MCCRUDDEN, Cristopher. Human dignity and judicial interpretation of human rights. The European Journal of International Law 19:655, 2008, p. 664.

52 McCRUDDEN, Cristopher. Human dignity and judicial interpretation of human rights. The European Journal of International Law 19:655, 2008.

53 BARROSO, Luís Roberto. A Dignidade da Pessoa Humana no Direito Constitucional
} 
complexidade dos temas transparece essa transformação valorativa que a dignidade da pessoa humana é envolta ao longo do tempo, não deixa dúvidas da complexidade da vida em social e da necessidade dos indivíduos em estabelecer uma definição mínima à dignidade humana para que seja instrumento eficaz de decisões justas.

Uma abordagem é dedicada à compreensão de um consenso mínimo valorativo e conceitual sobre a dignidade humana. E um questionamento é suscitado, se de fato, existe um núcleo mínimo sobre a dignidade humana nos textos jurídicos atuais? Estamos rumando a um núcleo mínimo na atual conjuntura jurídica? Nesse sentido, na visão de McCrudden ${ }^{54}$ perante a análise do discurso judicial atual sobre a dignidade humana é possível ir além de um núcleo consensual mínimo sobre a dignidade humana, para dar vasão ao seu argumento o autor apresenta um gama de decisões judiciais em inúmeras nações que levam em consideração a dignidade humana em suas interpretações jurídicas. Com destaque especial, as referências ao Ubuntu e a Patcha Mamma

the native African concept of 'ubuntu' : ' [g]enerally, ubuntu translates as humaneness. In its most fundamental sense, it translates as personhood and morality. Metaphorically, it expresses itself in umuntu ngumuntu gabantu, describing the significance of group solidarity on survival issues so central to the survival of communities. While it envelops the key values of group solidarity, compassion, respect, human dignity, conformity to basic norms and collective unity, in its fundamental sense it denotes humanity and morality. Its spirit emphasises respect for human dignity, marking a shift from confrontation to conciliation ${ }^{55}$

Como já abordado anteriormente, McCrudden ${ }^{56}$ também explana sobre

Contemporâneo: Natureza Jurídica, Conteúdos Mínimos e Critérios de Aplicação. Versão provisória para debate público. Mimeografado, dezembro de 2010. p. 8.

${ }_{54}$ McCRUDDEN, Cristopher. Human dignity and judicial interpretation of human rights. The European Journal of International Law 19:655, 2008. p. 675-.

55 Tradução livre: "O conceito africano nativo de 'ubuntu': 'geralemente é traduzido como humanidade. Em seu sentido mais fundamental, traduz-se como personalidade e moralidade. Metaforicamente, é expresso em umuntu ngumuntu gabantu, descrevendo o significado da solidariedade de grupo em questões de sobrevivência, o que é tão central para a sobrevivência das comunidades. Enquanto envolve os valores-chave da solidariedade de grupo, da compaixão, do respeito, da dignidade humana, da conformidade com as normas básicas e da unidade coletiva, no seu sentido fundamental denota humanidade e moralidade. Seu espírito enfatiza o respeito pela dignidade humana, marcando uma mudança do confronto para a conciliação" McCRUDDEN, Cristopher. Human dignity and judicial interpretation of human rights. The European Journal of International Law 19:655, 2008, p. 688.

${ }^{56}$ McCRUDDEN, Cristopher. Human dignity and judicial interpretation of human rights. The European Journal of International Law 19:655, 2008. p. 694-710. 
conceitos como pluralismo, relativismo, universalismo, naturalismo, individualismo, comunitarismo, que na visão do autor, permeiam a dificuldade de se criar um consenso mínimo valorativo sobre a dignidade humana. A dignidade, como assinalado, é um conceito cujo sentido e alcance sofrem influências históricas, religiosas e políticas, sendo suscetível de variação nas diferentes jurisdições. Nada obstante, a ambição do autor é a de buscar construir um sentido mínimo universalizável, aplicável a qualquer ser humano, onde quer que se encontre. Um esforço em busca de um conteúdo humanista, transnacional e transcultural. Nesse sentido, o autor observou a necessidade e a importância de se desenvolver uma concepção de dignidade humana que seja transnacional, tanscultural, não ideológica, humanista, não-positivista, individualista-emboracomunitarista! ${ }^{57}$

Adverte McCrudden ${ }^{58}$ que o uso do princípio da dignidade da pessoa humana não provê um princípio universal para a tomada de decisões judiciais no contexto dos direitos humanos, por haver um pequeno entendimento comum sobre o que, substancialmente, requeira a dignidade no exercício jurisdicional. Tal afirmação reflete o estágio atual de confusão em que se encontra a dimensão cultural da dignidade da pessoa humana, por faltar-lhe o ponto de referência da dimensão ontológica da dignidade da pessoa humana.

A análise da dignidade dentro de um discurso jurídico pode abrir o caminho para o estudo particular da dignidade da pessoa humana em âmbito histórico, social, cultural, político, legal, etc. A realidade, no entanto, é que o estudo da dignidade da pessoa humana, no discurso judicial, encontra-se no seu primeiro amanhecer, como dispõe o autor: "Analysis of dignity discourse in the judicial context is, however, in its relative infancy, and even fewer attempts have been made to provide cross-cultural studies of the use of dignity in judicial discourse using these richer methods" 59

A norma da dignidade da pessoa humana, na dimensão cultural, exige a

${ }^{57}$ MCCRUDDEN, Cristopher. Human dignity and judicial interpretation of human rights. The European Journal of International Law 19:655, 2008. p. 723.

${ }^{58}$ McCRUDDEN, Cristopher. Human dignity and judicial interpretation of human rights. The European Journal of International Law 19:655, 2008. p. 655.

59 Tradução livre: "Algumas jurisdições usam a dignidade como base para (ou outra maneira de expressar) um ponto de vista moral abrangente, como "uma visão de mundo moral completa", que parece distintamente diferente de região para região". McCRUDDEN, Cristopher. Human dignity and judicial interpretation of human rights. The European Journal of International Law 19:655, 2008. 
consideração entre texto-contexto seu significado e contexto-específico, sujeita a variações significativas perante jurisdições diferentes. Desse modo, a dignidade comportaria uma linguagem para a interpretação substantiva das garantias dos direitos humanos, que é muito contingente nas circunstâncias locais.

Apesar de a dignidade ter adquirido um posto central no ideal de direitos humanos universais, pode ser interpretada de modos diferentes. Além disso, há diferenças significativas no uso da dignidade quando são comparadas diversas normas que falam da dignidade, seja em âmbito internacional, regional e nacional, de modo que, em alguns documentos, a dignidade é encontrada apenas no preâmbulo; em outros, é empregada em relação a direitos particulares; em alguns, é tratada como fundamental, em outros, não; em alguns, é um direito por si mesmo; em outros, é um princípio geral, como é perceptível em algumas comparações entre textos regionais e textos internacionais. "[...] some jurisdictions use dignity as the basis for (or another way of expressing) a comprehensive moral viewpoint, as 'a whole moral world view', which seems distinctly different from region to region"60.

O exame de decisões judiciais que se fundaram na dignidade humana, em diferentes partes do mundo, revela a existência de uma visão comunitarista e restritiva de direitos, em oposição à visão individualista e protetiva de direitos. Em muitas situações, o conceito é utilizado como forma de impor um ponto de vista moral abrangente, que varia de lugar para lugar "o que emerge dessas diferenças é que algumas jurisdições usam a dignidade como a base para - ou como outro modo de expressar - um ponto de vista moral abrangente, que parece significativamente diferente de região para região". ${ }^{61}$

Demonstra o Barroso ${ }^{62}$ que a dignidade da pessoa humana nas cortes brasileiras é invocada como mero reforço argumentativo, uma vez que as jurisdições que envolvem a necessidade da utilização do princípio mais abstrato da dignidade humana já se encontram previstas em regras específicas de maior

60 Tradução livre: "A análise do discurso da dignidade no contexto judicial está, entretanto, na sua relativa infância, e muito poucas tentativas foram feitas para prover estudos transculturais do uso da dignidade no discurso judicial usando esses métodos mais ricos". McCRUDDEN, Cristopher. ibidem. p. 675.

${ }^{61}$ McCRUDDEN, Cristopher. Human dignity and judicial interpretation of human rights. The European Journal of International Law 19:655, 2008.

62 BARROSO, Luís Roberto. A Dignidade da Pessoa Humana no Direito Constitucional Contemporâneo: Natureza Jurídica, Conteúdos Mínimos e Critérios de Aplicação. Versão provisória para debate público. Mimeografado, dezembro de 2010. p. 30-31. 
densidade jurídica. Sendo seu principal âmbito de incidência situação que demanda ambiguidade de linguagem, lacuna normativa, colisão de normas constitucionais e direitos fundamentais e em desacordos morais razoáveis

A dignidade como parâmetro para a solução de casos difíceis é demonstrada pelo autor a partira da utilização dos conteúdos mínimos da dignidade - valor intrínseco, autonomia e valor comunitário - não elimina de maneira absoluta a subjetividade do intérprete. Mas pode ajudar a estruturar o raciocínio e a dar-lhe maior transparência, sobretudo em disputas judiciais envolvendo colisões de direitos ou desacordos morais.

A explicitação de cada um dos conteúdos da dignidade envolvidos na hipótese, bem como, a justificação das escolhas feitas em cada etapa, coíbem o voluntarismo e permitem um maior controle do raciocínio lógico desenvolvido pelo autor da decisão, inclusive para verificar se seus argumentos são laicos, politicamente neutros e universalizáveis.

Ao final do estudo, Barroso ${ }^{63}$ conclui no sentido de que a identificação da dignidade como um princípio jurídico e a determinação de seus conteúdos mínimos pode servir, dentre outras coisas, e em primeiro lugar, para unificar a utilização da expressão no âmbito doméstico e internacional. Facilita-se, assim, o seu emprego no discurso transnacional, pela uniformização, mediante convenção terminológica, das ideias que estão abrigadas na noção de dignidade humana. Em segundo lugar, ela contribui para estruturar o itinerário argumentativo na solução de casos difíceis, permitindo que se identifique cada um dos elementos relevantes, agrupando-os de acordo com cada conteúdo associado à dignidade. Isso poderá dar maior transparência ao processo decisório, possibilitando um controle social mais eficiente.

\section{CONSIDERAÇÕES FINAIS}

A dignidade da pessoa humana encontra-se progressivamente no núcleo do direito e da dogmática jurídica contemporânea. Encontra-se como primeiro princípio, fonte de todos os demais, núcleo do Estado de Direto. A sua utilização deverá restringir-se às questões em que nenhum outro princípio ou conceito jurídico possa ser utilizado, sob pena de ocorrer à dissolução de todo direito na dignidade. Tudo passa a ser então questão de dignidade e com isto o sistema

63 BARROSO, Luís Roberto. A Dignidade da Pessoa Humana no Direito Constitucional Contemporâneo: Natureza Jurídica, Conteúdos Mínimos e Critérios de Aplicação. Versão provisória para debate público. Mimeografado, dezembro de 2010. p. 39. 
jurídico esvazia-se de qualquer sentido normativo. A proliferação do uso indiscriminado do princípio da dignidade da pessoa humana na argumentação judicial faz com que se encontre onipresente, mesmo quando o próprio texto da lei atende às necessidades da ordem jurídica.

$\mathrm{Na}$ problemática suscitada pela dignidade humana que nos encontramos em face de um duplo desafio. Como conciliar a liberdade individual e o princípio que lhe é fundamental? Talvez a resposta encontre-se em se aceitar que a natureza do princípio da dignidade humana nos força reconhecer que o seu conteúdo, expresso nas máximas a que nos referimos, são os verdadeiros núcleos pétreos da vida humana, regulando de forma absoluta as relações interindividuais e entre a coletividade e os indivíduos.

Por essa razão, torna-se necessário a constante adequação lógico-racional do princípio da dignidade da pessoa humana a cada caso, retirando o mesmo do invólucro adjetivo em que foi envolvido pela prática jurídica. Verifica-se então como a dignidade humana encontra-se referida à questão não do indivíduo, mas da humanidade.

O presente trabalho buscou apresentar um conteúdo crítico sobre a dignidade da pessoa humana, diante de um contexto de mundo, cada vez mais globalizado e paradoxalmente local, cada vez mais plural e singular, torna-se imprescindível recolocar o papel discursivo e político dos direitos humanos. Percebe-se a necessidade crítica de um diálogo construtivo, intercultural em diferentes níveis que levem a conhecimentos e valores alternativos no que diz respeito a uma convivência humana pautada pela dignidade da pessoa humana, pela liberdade, pela ética, pela igualdade e pela justiça.

Como pano de fundo deste trabalho, real motivação do estado da arte e das indagações suscitadas ao logo do texto, esta a instigação de reflexões, através de uma análise filosófico-histórica mais aprofundada do conceito de dignidade da pessoa humana enquanto essência da humanidade. Razão pela qual, este trabalho visa contribuir com a construção do conhecimento em relação à dignidade da pessoa humana. 


\section{REFERÊNCIAS}

ABRAHAM, Marcus; PEREIRA, Vítor Pimentel. A influência da Torá nas Instituições Jurídicas Brasileiras. Revista do Instituto Histórico e Geográfico Brasileiro. Rio de Janeiro, a. 176. n. 466, pp. 11-270, jan./mar. 2015.

ALEXY, Robert. Teoria dos direitos fundamentais. Tradução Virgílio Afonso da silva. São Paulo: Malheiros, 2008.

BARCELLOS, Ana Paula de. A eficácia jurídica dos princípios constitucionais: o princípio da dignidade da pessoa humana. Rio de Janeiro: Renovar, 2002. p.103-104.

BARRETO, Vicente de Paulo; LEMOS, Fabrício José Rodrigues de. Uma abordagem compreensiva da Dignidade Humana. Quaestio Juris. vol. 08, ํㅡ. 03, Rio de Janeiro, 2015. pp. 1815-1826.

BARROSO, Luís Roberto. A Dignidade da Pessoa Humana no Direito Constitucional Contemporâneo: Natureza Jurídica, Conteúdos Mínimos e Critérios de Aplicação. Versão provisória para debate público. Mimeografado, dezembro de 2010.

COMPARATO, Fábio Konder. A afirmação histórica dos direitos humanos. São Paulo: Saraiva, 1999. p.20.

EDELMAN, Bernard. La dignité de la personne humaine, un concept nouveau. In: PAIVA, M.-L.; REVETT, Thierry. (Dir), La dignité de la personne. Paris : Econômica, 1999.

GUERRA, Sidney; EMERIQUE, Lilian Márcia Balmant. O princípio da dignidade da pessoa humana e o mínimo existencial. Revista da Faculdade de Direito de Campos, Ano VII, № 9 - Dezembro de 2006.

HABERMAS, Jürgen. Direito e democracia: entre facticidade e validade, 1997, v. 1, p. 160.

. O futuro da natureza humana: a caminho de uma eugenia liberal? 2.a ed. Trad. Karina Jannini. São Paulo: Martins Fontes, 2010. - p. 24.

KANT, Immanuel. Fundamentação da Metafísica dos Costumes. São Paulo: Martin Claret, 2008.

McCRUDDEN, Cristopher. Human dignity and judicial interpretation of human rights. The European Journal of International Law 19:655, 2008.

MIRANDOLA, Giovanni Pico Della. Discurso sobre a dignidade do homem. Tradução de Maria de Lurdes Sigardo Ganho. Lisboa: Edições 70, 1989.

PIOVESAN, Flávia; VIEIRA, Renato Stanziola. A força normativa dos princípios constitucionais fundamentais: a dignidade da pessoa humana. In: PIOVESAN, 
Flávia. Temas de direitos humanos. 3. ed. São Paulo: Saraiva, 2009.

ROCHA, Cármen Lúcia Antunes. O princípio da dignidade da pessoa humana e a exclusão social, texto mimeografado, em palestra proferida na XVII Conferência Nacional da Ordem dos Advogados do Brasil, Rio de Janeiro, 29-81999. p.8-9.

ROSEN, Michael. Dignidade: sua história e significado. Tradução de André de Godoy Vieira. São Leopoldo: Editora Unisinos, 2015.

SANTOS, Boaventura de Sousa. Se Deus fosse um ativista de direitos humanos. Cortez Editora, 2013.

SARLET, Ingo Wolfgang. A Eficácia dos Direitos Fundamentais. Porto Alegre. Livraria do advogado. Editora Ltda, 2005, p.35.

. Dignidade da pessoa humana e direitos fundamentais. Porto Alegre: Livraria do Advogado, 2001, p. 109-140.

. As dimensões da dignidade da pessoa humana: construindo uma compreensão jurídico-constitucional necessária e possível. Revista Brasileira de Direito Constitucional, n. 09, jan/jun, p. 361-388, 2007.

SARMENTO, Daniel. A ponderação de interesses na Constituição. Rio de Janeiro: Lúmen Juris, 2000.

. Direitos fundamentais e relações privada. Rio de Janeiro: Editora Lumen Juris, 2004.

. Dignidade da pessoa humana: conteúdo, trajetórias e metodologia. Belo. Horizonte: Fórum, 2016.

SILVA, José Afonso da. Poder constituinte e poder popular. São Paulo: Malheiros, 2000. 